\title{
An LMI Based Criterion for Global Asymptotic Stability of Discrete-Time State-Delayed Systems with Saturation Nonlinearities
}

\author{
Priyanka Kokil \\ Indian Institute of Information Technology, Design and Manufacturing, Kancheepuram, Chennai 600 127, India \\ Correspondence should be addressed to Priyanka Kokil; kokilnit@gmail.com
}

Received 3 June 2014; Revised 3 August 2014; Accepted 8 August 2014; Published 29 October 2014

Academic Editor: Fernando Tadeo

Copyright (C) 2014 Priyanka Kokil. This is an open access article distributed under the Creative Commons Attribution License, which permits unrestricted use, distribution, and reproduction in any medium, provided the original work is properly cited.

A linear matrix inequality (LMI) based criterion for the global asymptotic stability of discrete-time systems with multiple statedelays employing saturation nonlinearities is presented. Numerical examples highlighting the effectiveness of the proposed criterion are given.

\section{Introduction}

When discrete-time systems are implemented in finite word length processor using fixed-point arithmetic, nonlinearities are introduced due to quantization and overflow. Such nonlinearities may result in the instability of the designed system. The global asymptotic stability of the null solution guarantees the nonexistence of limit cycles in the realized system. A number of researchers [1-20] have extensively investigated the global asymptotic stability of discrete-time systems in the presence of overflow nonlinearities.

Time delays are generally encountered in various physi$\mathrm{cal}$, industrial, and engineering systems due to measurement and computational delays, transmission, and transport lags $[21,22]$. The presence of time delays may cause instability of the designed discrete-time systems. The problem of stability analysis of discrete-time state-delayed systems has drawn the attention of many researchers [23-37].

Stability analysis of discrete-time systems in the simultaneous presence of nonlinearities and time delays in their physical models is an important problem.

This paper, therefore, deals with the problem of stability analysis of a class of discrete-time state-delayed systems in state-space realization employing saturation overflow arithmetic. The paper is organized as follows. Section 2 introduces the system under consideration. A computationally tractable criterion for the global asymptotic stability of discretetime state-delayed systems employing saturation overflow arithmetic is established in Section 3. It is demonstrated in Section 4 that a previously reported criterion is recovered from the presented approach as a special case. In Section 5, two examples highlighting the effectiveness of the presented approach are given.

\section{System Description}

In this section, the description of the system under consideration is given. The following notations are used throughout the paper:

$\mathbf{R}^{p \times q}$ : set of $p \times q$ real matrices,

$\mathbf{R}^{p}$ : set of $p \times 1$ real vectors,

0: null matrix or null vector of appropriate dimensions,

I: identity matrix of appropriate dimensions,

$\mathbf{B}^{T}$ : transpose of a matrix (or vector) $\mathbf{B}$,

B $>\mathbf{0}$ : $\mathbf{B}$ is positive definite symmetric matrix,

$\|\cdot\|$ : any vector norm or matrix norm. 
The system under consideration is given by

$$
\begin{aligned}
& \mathbf{x}(k+1)= \mathbf{f}(\mathbf{y}(k)) \\
&= {\left[\begin{array}{llll}
f_{1}\left(y_{1}(k)\right) & f_{2}\left(y_{2}(k)\right) & \cdots & f_{n}\left(y_{n}(k)\right)
\end{array}\right]^{T}, } \\
& \mathbf{y}(k)=\mathbf{A x}(k)+\sum_{i=1}^{m} \mathbf{A}_{d_{i}} \mathbf{x}\left(k-d_{i}\right)
\end{aligned}
$$

where $\mathbf{x}(k) \in \mathbf{R}^{n}$ is the state vector; $\mathbf{A}, \mathbf{A}_{d_{i}}(i=1,2, \ldots, m) \in$ $\mathbf{R}^{n \times n}$ are the known constant matrices; $d_{i}(i=1,2, \ldots, m)$ is the positive integer for time delays; and $\boldsymbol{\varphi}(k) \in \mathbf{R}^{n}$ is the initial state value at time $k$. The function $f_{i}\left(y_{i}(k)\right)$ representing the saturation nonlinearities given by

$$
\begin{aligned}
& f_{i}\left(y_{i}(k)\right)= \begin{cases}1, & y_{i}(k)>1 \\
y_{i}(k), & -1 \leq y_{i}(k) \leq 1 \\
-1, & y_{i}(k)<-1,\end{cases} \\
& i=1,2, \ldots, n,
\end{aligned}
$$

is under consideration.

Let

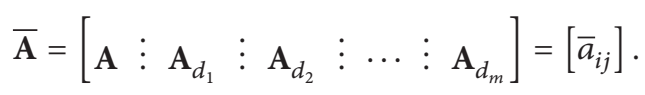

Define [14]

$$
s_{i}=\sum_{j=1}^{n(m+1)}\left|\bar{a}_{i j}\right|, \quad i=1,2, \ldots, n
$$

and assume that the elements of the matrix $\overline{\mathbf{A}}$ satisfy

$$
\begin{aligned}
& s_{i}>1, \quad i=1,2, \ldots, q \\
& s_{i} \leq 1, \quad i=q+1, q+2, \ldots, n,
\end{aligned}
$$

where $q$ is an integer between 0 and $n$. Such assumption does not pose any real difficulty due to the fact that, by relabeling the states, any discrete-time system can easily be transformed into an equivalent system such that (5a) and (5b) hold.

A class of discrete-time systems can be described with (1a), (1b), (1c), (1d), and (2); it includes digital filters implemented in finite word length [1-18], digital control systems with saturation arithmetic [5], neural networks defined on hypercubes [38], and so forth.

The equilibrium state $\mathbf{x}_{e}=\mathbf{0}$ of the system (1a), (1b), (1c), (1d), and (2) is asymptotically stable, if, for any $\varepsilon>0$, there exists $\beta>0$ such that if $\|\phi(k)\|<\beta, k=-d,-d+1, \ldots, 0$, then $\|\mathbf{x}(k)\|<\varepsilon$, for every $k \geq 0$ and $\lim _{k \rightarrow \infty} \mathbf{x}(k)=\mathbf{0}$.

\section{Main Results}

In this section, a linear matrix inequality (LMI) based criterion for the global asymptotic stability of the system (1a), (1b), (1c), (1d), (2), (4), (5a), and (5b) is established.

Suppose $\mathbf{C}=\left[c_{i j}\right] \in \mathbf{R}^{n \times n}$ is a matrix characterized by

$$
\begin{gathered}
c_{i i}=\sum_{j=1, j \neq i}^{n}\left(\alpha_{i j}+\beta_{i j}\right), \quad i=1,2, \ldots, q, \\
c_{i j}=\left\{\begin{array}{c}
\alpha_{i j}-\beta_{i j}, \\
i, j=1,2, \ldots, q(i \neq j), \\
\frac{\alpha_{i j}-\beta_{i j}}{s_{j}}, \\
i=1,2, \ldots, q, j=q+1, q+2, \ldots, n(i \neq j), \\
i=1,2, \ldots, q, \quad j=1,2, \ldots, n \quad(i \neq j),
\end{array}\right.
\end{gathered}
$$

where it is implicit that, for $n=1, \mathbf{C}$ corresponds to a scalar $\mu>0$.

For $n=3$ and $q=2$, the matrix $\mathbf{C}$ takes the form

$$
\mathbf{C}=\left[\begin{array}{ccc}
\alpha_{12}+\beta_{12}+\alpha_{13}+\beta_{13} & \alpha_{12}-\beta_{12} & \frac{\alpha_{13}-\beta_{13}}{s_{3}} \\
\alpha_{21}-\beta_{21} & \alpha_{21}+\beta_{21}+\alpha_{23}+\beta_{23} & \frac{\alpha_{23}-\beta_{23}}{s_{3}} \\
c_{31} & c_{32} & c_{33}
\end{array}\right],
$$

where $\alpha_{i j}>0$ and $\beta_{i j}>0 i=1,2, j=1,2,3(i \neq j)$.

Now, we have the following lemma.

Lemma 1. The matrix $\mathbf{C}=\left[c_{i j}\right] \in \mathbf{R}^{n \times n}$ defined by (6a), (6b), and $(6 \mathrm{c})$ satisfies

$$
\begin{array}{r}
c_{i i} \geq \sum_{j=1, j \neq i}^{q}\left|c_{i j}\right|+\sum_{j=q+1, j \neq i}^{n} s_{j}\left|c_{i j}\right|, \\
i=1,2, \ldots, q .
\end{array}
$$

Proof. Using (6a), (6b), and (6c), we obtain

$$
\begin{aligned}
c_{i i} & =\sum_{j=1, j \neq i}^{n}\left(\alpha_{i j}+\beta_{i j}\right) \\
& =\sum_{j=1, j \neq i}^{q}\left(\alpha_{i j}+\beta_{i j}\right)+\sum_{j=q+1, j \neq i}^{n}\left(\alpha_{i j}+\beta_{i j}\right) \\
& >\sum_{j=1, j \neq i}^{q}\left|\alpha_{i j}-\beta_{i j}\right|+\sum_{j=q+1, j \neq i}^{n} s_{j} \frac{\left|\alpha_{i j}-\beta_{i j}\right|}{s_{j}} \\
& =\sum_{j=1, j \neq i}^{q}\left|c_{i j}\right|+\sum_{j=q+1, j \neq i}^{n} s_{j}\left|c_{i j}\right|, \quad i=1,2, \ldots, q .
\end{aligned}
$$

This completes the proof of Lemma 1.

Now, we prove our main result. 
Theorem 2. The zero solution of the system described by (1a), (1b), (1c), (1d), (2), (4), (5a), and (5b) is globally asymptotically stable if there exist positive scalars $\alpha_{i j}, \beta_{i j} i=1,2, \ldots, q, j=$ $1,2, \ldots, n(i \neq j)$ and positive definite symmetric matrices $\mathbf{P} \in$ $\mathbf{R}^{n \times n}, \mathbf{Q}_{i} \in \mathbf{R}^{n \times n}(i=1,2, \ldots, m)$ such that the following $L M I$ holds:

$$
\mathbf{Z}=\left[\begin{array}{ccccc}
\mathbf{P}-\sum_{i=1}^{m} \mathbf{Q}_{i} & \mathbf{0} & \ldots & \mathbf{0} & -\mathbf{A}^{T} \mathbf{C} \\
\mathbf{0} & \mathbf{Q}_{1} & \ldots & \mathbf{0} & -\mathbf{A}_{d_{1}}{ }^{T} \mathbf{C} \\
\vdots & \vdots & \ddots & \vdots & \vdots \\
\mathbf{0} & \mathbf{0} & \ldots & \mathbf{Q}_{m} & -\mathbf{A}_{d_{m}}{ }^{T} \mathbf{C} \\
-\mathbf{C}^{T} \mathbf{A} & -\mathbf{C}^{T} \mathbf{A}_{d_{1}} & \ldots & -\mathbf{C}^{T} \mathbf{A}_{d_{m}} & -\mathbf{P}+\mathbf{C}+\mathbf{C}^{T}
\end{array}\right]>\mathbf{0}
$$

where $\mathbf{C}$ is characterized by (6a), (6b), and (6c).

Proof. Let

$$
\widehat{\mathbf{x}}(k)=\left[\begin{array}{lllll}
\mathbf{x}^{T}(k) & \mathbf{x}^{T}\left(k-d_{1}\right) & \mathbf{x}^{T}\left(k-d_{2}\right) & \cdots & \mathbf{x}^{T}\left(k-d_{m}\right)
\end{array}\right]^{T} .
$$

In view of (1a), (1b), (1c), (1d), we have

$$
\left|\widehat{x}_{i}(k)\right| \leq 1, \quad i=1,2, \ldots, n(m+1) .
$$

Using (1b), (12), and (5b), one obtains

$$
\begin{aligned}
\left|y_{i}(k)\right| & =\left|\sum_{j=1}^{n(m+1)} \bar{a}_{i j} \widehat{x}_{j}(k)\right| \\
& \leq \sum_{j=1}^{n(m+1)}\left|\bar{a}_{i j}\right|\left|\widehat{x}_{j}(k)\right| \\
& \leq \sum_{j=1}^{n(m+1)}\left|\bar{a}_{i j}\right|=s_{i}, \quad i=1,2, \ldots, n .
\end{aligned}
$$

It follows from (5b) and (13) that

$$
\left|y_{i}(k)\right| \leq 1, \quad i=q+1, q+2, \ldots, n,
$$

which, together with (2), yields

$$
f_{i}\left(y_{i}(k)\right)=y_{i}(k), \quad i=q+1, q+2, \ldots, n .
$$

Consider a quadratic Lyapunov function [19]

$$
v(\mathbf{x}(k))=\mathbf{x}^{T}(k) \mathbf{P} \mathbf{x}(k)+\sum_{i=1}^{m} \sum_{j=-d_{i}}^{-1} \mathbf{x}^{T}(k+j) \mathbf{Q}_{i} \mathbf{x}(k+j) .
$$

Application of (16) to (1a), (1b), (1c), and (1d) gives

$$
\begin{aligned}
\Delta v(\mathbf{x}(k))= & v(\mathbf{x}(k+1))-v(\mathbf{x}(k)) \\
= & \mathbf{f}^{T}(\mathbf{y}(k)) \mathbf{P f}(\mathbf{y}(k))-\mathbf{x}^{T}(k)\left[\mathbf{P}-\sum_{i=1}^{m} \mathbf{Q}_{i}\right] \mathbf{x}(k) \\
& -\sum_{i=1}^{m} \mathbf{x}^{T}\left(k-d_{i}\right) \mathbf{Q}_{i} \mathbf{x}\left(k-d_{i}\right)
\end{aligned}
$$

Now choose the quantity " $\delta$ " as [14]

$$
\begin{aligned}
\delta= & 2 \sum_{i=1}^{q}\left[y_{i}(k)-f_{i}\left(y_{i}(k)\right)\right] \\
\times & {\left[c_{i i} f_{i}\left(y_{i}(k)\right)+\sum_{j=1, j \neq i}^{q} c_{i j} f_{j}\left(y_{j}(k)\right)\right.} \\
& \left.+\sum_{j=q+1, j \neq i}^{n} c_{i j} s_{j} \frac{f_{j}\left(y_{j}(k)\right)}{s_{j}}\right] \\
+ & 2 \sum_{i=q+1}^{n}\left[y_{i}(k)-f_{i}\left(y_{i}(k)\right)\right] \\
& \times\left[c_{i i} f_{i}\left(y_{i}(k)\right)+\sum_{j=1, j \neq i}^{n} c_{i j} f_{j}\left(y_{j}(k)\right)\right],
\end{aligned}
$$

when $n \geq 2$ and

$$
\delta=2 \mu\left[y_{1}(k)-f_{1}\left(y_{1}(k)\right)\right] f_{1}\left(y_{1}(k)\right),
$$

when $n=1$.

From (13) and (15), we obtain

$$
\left|f_{i}\left(y_{i}(k)\right)\right|=\left|y_{i}(k)\right| \leq s_{i}, \quad i=q+1, q+2, \ldots, n .
$$

Therefore,

$$
\left|\frac{f_{j}\left(y_{j}(k)\right)}{s_{j}}\right| \leq 1, \quad j=q+1, q+2, \ldots, n .
$$

Using Lemma 1 and (21), it is easy to show that the first term of (18) is nonnegative for the nonlinearities given by (2) if (8) is satisfied. In view of (15), the second term of (18) is zero. Thus, the quantity " $\delta$ " given by $(18)$ is nonnegative. Equation (18) can also be expressed as

$$
\begin{gathered}
\delta=\mathbf{y}^{T}(k) \mathbf{C} \mathbf{f}(\mathbf{y}(k))+\mathbf{f}^{T}(\mathbf{y}(k)) \mathbf{C}^{T} \mathbf{y}(k) \\
-\mathbf{f}^{T}(\mathbf{y}(k))\left(\mathbf{C}+\mathbf{C}^{T}\right) \mathbf{f}(\mathbf{y}(k)) .
\end{gathered}
$$

Adding to and subtracting from (17), the quantity " $\delta$ " yields, after some rearrangement,

$$
\Delta v(\mathbf{x}(k))=-\widetilde{\mathbf{x}}^{T}(k) \mathbf{Z} \widetilde{\mathbf{x}}(k)-\delta,
$$

where

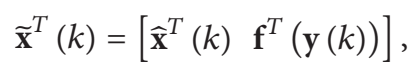

and $\mathbf{Z}$ is given by (10). Therefore, if $\mathbf{Z}>\mathbf{0}$, then $\Delta v(\mathbf{x}(k))<\mathbf{0}$ for $\widetilde{\mathbf{x}}(k) \neq \mathbf{0}$. Thus, condition $\mathbf{Z}>\mathbf{0}$ is a sufficient condition for the global asymptotic stability of the system (1a), (1b), (1c), (1d), (2), (4), (5a), (5b), and $\Delta v(\mathbf{x}(k))=0$ only when $\widetilde{\mathbf{x}}(k)=\mathbf{0}$.

This completes the proof of Theorem 2 .

Remark 3. The matrix inequality (10) is linear in the unknown parameters $\alpha_{i j}, \beta_{i j}(i=1,2, \ldots, q, j=1,2, \ldots, n$ $(i \neq j)), \mathbf{P}$, and $\mathbf{Q}_{i}(i=1,2, \ldots, m)$. Thus, it can be easily solved using MATLAB LMI toolbox $[39,40]$. 
Remark 4. Note that condition (10) is independent of the delay. Therefore, one need not know the size of the delays to establish the global asymptotic stability of the system (1a), (1b), (1c), (1d), (2), (4), (5a) and (5b) via Theorem 2.

Remark 5. Condition (10) provides a limit cycle-free realizability condition for the system with saturation arithmetic.

Remark 6. Stability of the system can be established via Theorem 2 for one combination of the elements of the matrix $\overline{\mathbf{A}}$, that is, where the elements of first $q$ rows of $\overline{\mathbf{A}}$ satisfy (5a) and those of the remaining $(n-q)$ rows satisfy $(5 b)$. The stability results for the other possible combinations of the elements of matrix $\overline{\mathbf{A}}$ can easily be worked out.

\section{Comparison}

In this section, we will compare the main result of this paper with the result stated in [41].

Theorem 7 (see [41]). The zero solution of the system described by (1a), (1b), (1c), (1d), (2), and (4) is globally asymptotically stable if there exist $n \times n$ positive definite symmetric matrices $\mathbf{P}=\left[p_{i j}\right]$ and $\mathbf{Q}_{i}(i=1,2, \ldots, m)$ such that

$$
\begin{gathered}
{\left[\begin{array}{ccccc}
\mathbf{P}-\sum_{i=1}^{m} \mathbf{Q}_{i} & \mathbf{0} & \ldots & \mathbf{0} & -\mathbf{A}^{T} \mathbf{P} \\
\mathbf{0} & \mathbf{Q}_{1} & \ldots & \mathbf{0} & -\mathbf{A}_{d_{1}}{ }^{T} \mathbf{P} \\
\vdots & \vdots & \ddots & \vdots & \vdots \\
\mathbf{0} & \mathbf{0} & \ldots & \mathbf{Q}_{m} & -\mathbf{A}_{d_{m}}{ }^{T} \mathbf{P} \\
-\mathbf{P A} & -\mathbf{P} \mathbf{A}_{d_{1}} & \ldots & -\mathbf{P A} d_{m} & \mathbf{P}
\end{array}\right]>\mathbf{0}} \\
p_{i i} \geq \sum_{j=1, j \neq i}^{q}\left|p_{i j}\right|+\sum_{j=q+1, j \neq i}^{n} k_{j}\left|p_{i j}\right|, \quad i=1,2, \ldots, q .
\end{gathered}
$$

Proposition 8. Theorem 2 implies Theorem 7.

Proof. It can be easily conceived that, with

$$
\mathbf{C}=\mathbf{C}^{T}=\mathbf{P}
$$

matrix $\mathbf{C}$ reduces to a positive definite symmetric matrix $\mathbf{P}$; as a result, (10) reduces to (25). Therefore, Theorem 7 is recovered from Theorem 2 as a special case.

Remark 9. The present work may be treated as an extension of [41]. Moreover, the present approach leads to generalized and improved result over the result appearing in [41].

\section{Numerical Examples}

In this section, two numerical examples are given to demonstrate the usefulness of the present result.

Example 1. Consider a second-order system (1a), (1b), (1c), (1d), (2), (4), (5a), and (5b) with

$$
\mathbf{A}=\left[\begin{array}{cc}
1.7 & -2.5 \\
0.3 & 0.1
\end{array}\right], \quad \mathbf{A}_{d_{1}}=\left[\begin{array}{cc}
0 & 0.001 \\
0.001 & 0
\end{array}\right]
$$

Here, $s_{1}=4.201>1, s_{2}=0.401<1, m=1$, and $q=$ 1. Using MATLAB LMI toolbox $[39,40]$, it can be verified that Theorem 7 does not provide any feasible solution for this example.

We now apply Theorem 2 in the example under consideration. To check the feasibility of (10), we choose the matrix $\mathbf{C}$ in the following form:

$$
\mathbf{C}=\left[\begin{array}{cc}
\alpha_{12}+\beta_{12} & \frac{\alpha_{12}-\beta_{12}}{s_{2}} \\
c_{21} & c_{22}
\end{array}\right],
$$

where $\alpha_{12}>0$ and $\beta_{12}>0$. With the help of MATLAB LMI toolbox $[39,40]$, it turns out that (10) yields the following solutions for the present system:

$$
\begin{gathered}
\mathbf{P}=\left[\begin{array}{cc}
3.7407 & -9.7872 \\
-9.7872 & 30.3330
\end{array}\right], \quad \mathbf{Q}_{1}=\left[\begin{array}{cc}
0.1201 & -0.3006 \\
-0.3006 & 1.0939
\end{array}\right], \\
\mathbf{C}=\left[\begin{array}{cc}
3.5890 & -8.6693 \\
-9.3390 & 27.3297
\end{array}\right], \\
\left(\alpha_{12}=0.0563, \quad \beta_{12}=3.5327\right) .
\end{gathered}
$$

Therefore, Theorem 2 affirms the global asymptotic stability of the present system. Figure 1 shows the trajectory of the state variable for the present example with

$$
x(0)=\left[\begin{array}{l}
0.1 \\
0.1
\end{array}\right], \quad x(-1)=\left[\begin{array}{l}
0.01 \\
0.01
\end{array}\right] .
$$

The global asymptotic stability of the system under consideration (via Theorem 2) has also been verified for a number of randomly generated initial conditions with the help of trajectories traces of the system.

Example 2. Consider a system described by (1a), (1b), (1c), (1d), (2), (4), (5a), and (5b) with

$$
\begin{gathered}
\mathbf{A}=\left[\begin{array}{cc}
0.25 & -2.5 \\
0.3 & 0.1
\end{array}\right], \quad \mathbf{A}_{d_{1}}=\left[\begin{array}{cc}
0 & 0.001 \\
0.001 & 0
\end{array}\right], \\
\mathbf{A}_{d_{2}}=\left[\begin{array}{cc}
0 & 0.001 \\
0.001 & 0
\end{array}\right] .
\end{gathered}
$$

Here, $s_{1}=2.752>1, s_{2}=0.402<1, q=1$, and $m=2$. Using MATLAB LMI toolbox $[39,40]$, it can be verified that (10) leads to the following feasible solutions:

$$
\begin{aligned}
& \mathbf{P}=\left[\begin{array}{cc}
46.2533 & -10.7064 \\
-10.7064 & 364.9293
\end{array}\right], \\
& \mathbf{Q}_{1}=\mathbf{Q}_{2}=\left[\begin{array}{cc}
4.6440 & -0.6299 \\
-0.6299 & 25.7668
\end{array}\right], \\
& \mathbf{C}=\left[\begin{array}{ll}
47.5470 & -12.7868 \\
-8.9295 & 316.4069
\end{array}\right], \\
&\left(\alpha_{12}=21.2034, \beta_{12}=26.3436\right) .
\end{aligned}
$$

Therefore, for this example, Theorem 2 succeeds to determine the global asymptotic stability of the system. However, (25) becomes infeasible and, consequently, Theorem 7 fails to ensure the global asymptotic stability of the present example. 


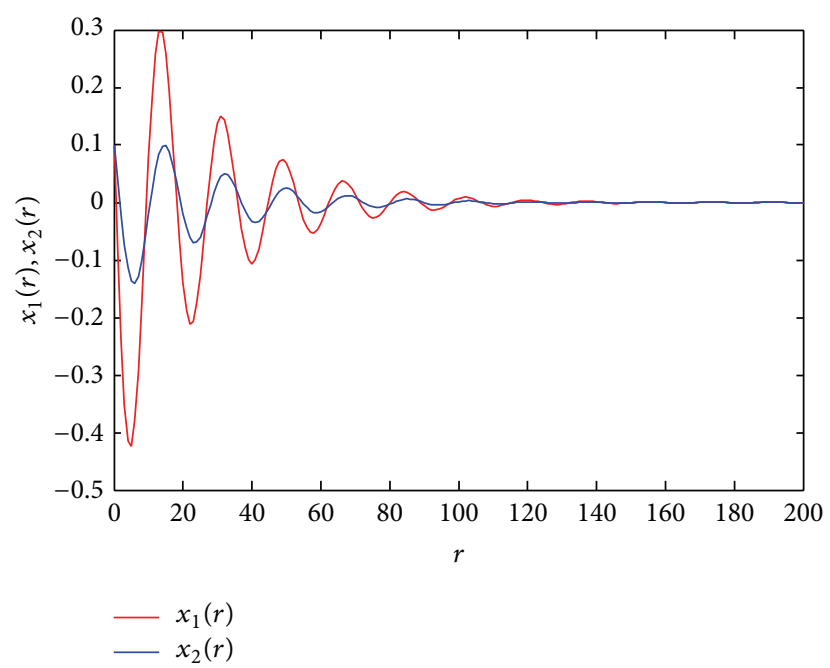

Figure 1: Trajectory for the state variables.

\section{Conclusions}

An LMI-based sufficient condition (Theorem 2) for the global asymptotic stability of discrete-time systems with multiple state-delays employing saturation nonlinearities has been established. It is shown that Theorem 2 is less stringent than Theorem 7. Two numerical examples highlighting the usefulness of the presented result have been discussed.

The potential extensions of the proposed idea to the problems of stability of linear discrete-time systems with intervallike time-varying delay in the state $[42,43]$, stability of fixedpoint state-space digital filters with saturation arithmetic [44], robust stability of discrete-time state-delayed systems using generalized overflow nonlinearities [19], stability of linear systems with input saturation and asymmetric constraints on the control increment or rate [45], and stability of linear two-dimensional systems with multidelays and input saturation [46], to other situations such as [47, 48], appear to be appealing problems for future investigation.

\section{Conflict of Interests}

The author declares that there is no conflict of interests regarding the publication of this paper.

\section{Acknowledgments}

The author wishes to thank Professor Fernando Tadeo and the anonymous reviewers for their constructive comments and suggestions.

\section{References}

[1] J. H. F. Ritzerfeld, "Condition for the overflow stability of second-order digital filters that is satisfied by all scaled statespace structures using saturation," IEEE transactions on circuits and systems, vol. 36, no. 8, pp. 1049-1057, 1989.

[2] V. Singh, "A new realizability condition for limit cycle-free state-space digital filters employing saturation arithmetic," IEEE
Transactions on Circuits and Systems, vol. 32, no. 10, pp. 10701071, 1985.

[3] V. Singh, "Elimination of overflow oscillations in fixed-point state-space digital filters using saturation arithmetic," IEEE Transactions on Circuits and Systems, vol. 37, no. 6, pp. 814-818, 1990.

[4] T. Bose and M. Chen, "Overflow oscillations in state-space digital filters," IEEE transactions on circuits and systems, vol. 38, no. 7, pp. 807-810, 1991.

[5] D. Liu and A. N. Michel, "Asymptotic stability of discrete-time systems with saturation nonlinearities with applications to digital filters," IEEE Transactions on Circuits and Systems I: Fundamental Theory and Applications, vol. 39, no. 10, pp. 798-807, 1992.

[6] H. Kar and V. Singh, "A new criterion for the overflow stability of second-order state-space digital filters using saturation arithmetic," IEEE Transactions on Circuits and Systems I, vol. 45, no. 3, pp. 311-313, 1998.

[7] H. Kar and V. Singh, "Stability analysis of discrete-time systems in a state-space realisation with partial state saturation nonlinearities," IEE Proceedings: Control Theory and Applications, vol. 150, no. 3, pp. 205-208, 2003.

[8] T. Ooba, "Stability of linear discrete dynamics employing state saturation arithmetic," IEEE Transactions on Automatic Control, vol. 48, no. 4, pp. 626-630, 2003.

[9] H. Kar and V. Singh, "Elimination of overflow oscillations in fixed-point state-space digital filters with saturation arithmetic: an LMI approach," IEEE Transactions on Circuits and Systems II: Express Briefs, vol. 51, no. 1, pp. 40-42, 2004.

[10] V. Singh, "Stability analysis of discrete-time systems in a statespace realisation with state saturation nonlinearities: Linear matrix inequality approach," IEE Proceedings Control Theory and Applications, vol. 152, no. 1, pp. 9-12, 2005.

[11] H. Kar and V. Singh, "Elimination of overflow oscillations in digital filters employing saturation arithmetic," Digital Signal Processing, vol. 15, no. 6, pp. 536-544, 2005.

[12] H. Kar, "An LMI based criterion for the nonexistence of overflow oscillations in fixed-point state-space digital filters using saturation arithmetic," Digital Signal Processing, vol. 17, no. 3, pp. 685-689, 2007.

[13] V. Singh, "Modified form of Liu-Michel's criterion for global asymptotic stability of fixed-point state-space digital filters using saturation arithmetic," IEEE Transactions on Circuits and Systems II, vol. 53, no. 12, pp. 1423-1425, 2006.

[14] H. Kar, "An improved version of modified Liu-Michel's criterion for global asymptotic stability of fixed-point state-space digital filters using saturation arithmetic," Digital Signal Processing, vol. 20, no. 4, pp. 977-981, 2010.

[15] V. Singh, "Novel criterion for stability of discrete-time systems in a state-space realization utilizing saturation nonlinearities," Applied Mathematics and Computation, vol. 218, no. 8, pp. 43054311, 2011.

[16] V. Singh, "New criterion for stability of discrete-time systems joined with a saturation operator on the state-space," $A E U$ International Journal of Electronics and Communications, vol. 66, no. 6, pp. 509-511, 2012.

[17] V. Singh, "Stability of discrete-time systems joined with a saturation operator on the state-space: yet another version of Liu-Michel's criterion," AEÜ International Journal of Electronics and Communications, vol. 66, no. 1, pp. 28-31, 2012. 
[18] P. Kokil, V. K. R. Kandanvli, and H. Kar, "A note on the criterion for the elimination of overflow oscillations in fixed-point digital filters with saturation arithmetic and external disturbance," AEÜ-International Journal of Electronics and Communications, vol. 66, no. 9, pp. 780-783, 2012.

[19] V. Krishna Rao Kandanvli and H. Kar, "Robust stability of discrete-time state-delayed systems employing generalized overflow nonlinearities," Nonlinear Analysis, Theory, Methods and Applications, vol. 69, no. 9, pp. 2780-2787, 2008.

[20] V. Krishna Rao Kandanvli and H. Kar, "Robust stability of discrete-time state-delayed systems with saturation nonlinearities: linear matrix inequality approach," Signal Processing, vol. 89, no. 2, pp. 161-173, 2009.

[21] M. S. Mahmoud, Robust Control and Filtering for Time-Delay Systems, vol. 5 of Control Engineering, Marcel Dekker, New York, NY, USA, 2000.

[22] M. Malek-Zavarei and M. Jamshidi, Time-Delay Systems: Analysis, Optimization and Applications, North-Holland, Amsterdam, The Netherlands, 1987.

[23] J. K. Hale, Functional Differential Equations, Springer, New York, NY, USA, 1971.

[24] J. Richard, "Time-delay systems: an overview of some recent advances and open problems," Automatica, vol. 39, no. 10, pp. 1667-1694, 2003.

[25] H. Shao, "Delay-dependent approaches to globally exponential stability for recurrent neural networks," IEEE Transactions on Circuits and Systems II, vol. 55, no. 6, pp. 591-595, 2008.

[26] H. Huang and G. Feng, "Improved approach to delay-dependent stability analysis of discrete-time systems with time-varying delay," IET Control Theory and Applications, vol. 4, no. 10, pp. 2152-2159, 2010.

[27] V. K. R. Kandanvli and H. Kar, "An LMI condition for robust stability of discrete-time state-delayed systems using quantization/overflow nonlinearities," Signal Processing, vol. 89, no. 11, pp. 2092-2102, 2009.

[28] S. Xu, "Robust $H_{\infty}$ filtering for a class of discrete-time uncertain nonlinear systems with state delay," IEEE Transactions on Circuits and Systems I: Fundamental Theory and Applications, vol. 49, no. 12, pp. 1853-1859, 2002.

[29] S. Xu, J. Lam, and T. Chen, "Robust $H_{\infty}$ control for uncertain discrete stochastic time-delay systems," Systems and Control Letters, vol. 51, no. 3-4, pp. 203-215, 2004.

[30] G. Lu and D. W. C. Ho, "Robust observer for nonlinear discrete systems with time delay and parameter uncertainties," IEE Proceedings-Control Theory and Applications, vol. 151, no. 4, pp. 439-444, 2004.

[31] R. M. Palhares, C. E. de Souza, and P. L. D. Peres, "Robust $H_{\infty}$ filtering for uncertain discrete-time state-delayed systems," IEEE Transactions on Signal Processing, vol. 49, no. 8, pp. 16961703, 2001.

[32] W. Chen, Z. Guan, and X. Lu, "Delay-dependent guaranteed cost control for uncertain discrete-time systems with both state and input delays," Journal of the Franklin Institute, vol. 341, no. 5, pp. 419-430, 2004.

[33] X. Guan, Z. Lin, and G. Duan, "Robust guaranteed cost control for discrete-time uncertain systems with delay," IEE Proceedings-Control Theory and Applications, vol. 146, no. 6, pp. 598-602, 1999.

[34] L. Bakule, J. Rodellar, and J. M. Rossell, "Robust overlapping guaranteed cost control of uncertain state-delay discrete-time systems," IEEE Transactions on Automatic Control, vol. 51, no. 12, pp. 1943-1950, 2006.
[35] W.-H. Chen, Z.-H. Guan, and X. Lu, "Delay-dependent guaranteed cost control for uncertain discrete-time systems with delay," IEE Proceedings: Control Theory and Applications, vol. 150, no. 4, pp. 412-416, 2003.

[36] J. H. Kim and S. J. Ahn, "Guaranteed cost and $H_{\infty}$ filtering for discrete-time polytopic uncertain systems with time delay," Journal of the Franklin Institute, vol. 342, no. 4, pp. 365-378, 2005.

[37] M. S. Mahmoud, E. Boukas, and A. Ismail, "Robust adaptive control of uncertain discrete-time state-delay systems," Computers and Mathematics with Applications, vol. 55, no. 12, pp. 28872902, 2008.

[38] A. N. Michel, J. Si, and G. Yen, "Analysis and synthesis of a class of discrete-time neural networks described on hypercubes," IEEE Transactions on Neural Networks, vol. 2, no. 1, pp. 32-46, 1991.

[39] P. Gahinet, A. Nemirovski, A. J. Laub, and M. Chilali, LMI Control Toolbox for use with Matlab, The MathWorks, Natick, Mass, USA, 1995.

[40] S. Boyd, L. El Ghaoui, and E. Feron, Linear Matrix Inequalities in System and Control Theory, vol. 15, SIAM, Philadelphia, Pa, USA, 1994.

[41] P. Kokil, H. Kar, and V. K. R. Kandanvli, "Stability analysis of discrete-time state-delayed systems with saturation nonlinearities," in Proceedings of the 2011 International Conference on Computational Intelligence and Computing Research, Kanyakumari, India, 2011.

[42] P. Kokil, H. Kar, and V. K. R. Kandanvli, "Stability analysis of linear discrete-time systems with interval delay: a delay-partitioning approach," ISRN Applied Mathematics, vol. 2011, Article ID 624127, 10 pages, 2011.

[43] P. Kokil, V. K. R. Kandanvli, and H. Kar, "Delay-partitioning approach to stability of linear discrete-time systems with interval-like time-varying delay," International Journal of Engineering Mathematics, vol. 2013, Article ID 291976, 7 pages, 2013.

[44] P. Kokil and H. Kar, "An improved criterion for the global asymptotic stability of fixed-point state-space digital filters with saturation arithmetic," Digital Signal Processing, vol. 22, no. 6, pp. 1063-1067, 2012.

[45] A. Benzaouia, F. Tadeo, and F. Mesquine, "The regulator problem for linear systems with saturations on the control and its increments or rate: an LMI approach," IEEE Transactions on Circuits and Systems I: Regular Papers, vol. 53, no. 12, pp. 26812691, 2006

[46] M. Benhayoun, A. Benzaouia, F. Mesquine, and F. Tadeo, "Stabilization of 2D continuous systems with multi-delays and saturated control," in Proceeding of the 18th Mediterranean Conference on Control and Automation (MED '10), pp. 993-999, Marrakech, Morocco, June 2010.

[47] T. Hu, Z. Lin, and B. M. Chen, "Analysis and design for discretetime linear systems subject to actuator saturation," Systems and Control Letters, vol. 45, no. 2, pp. 97-112, 2002.

[48] T. Hu and Z. Lin, "The equivalence of several set invariance conditions under saturation," in Proceeding of the 41st IEEE Conference on Decision and Control, pp. 4146-4147, Las Vegas, Nev, USA, December 2002. 


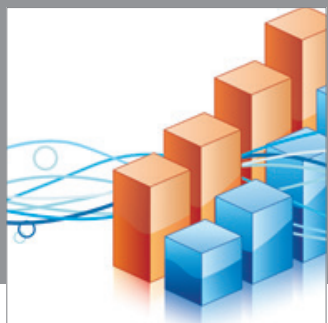

Advances in

Operations Research

mansans

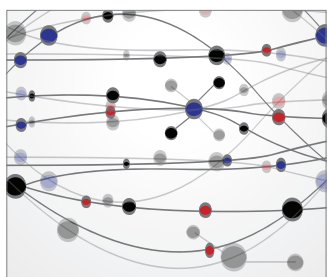

The Scientific World Journal
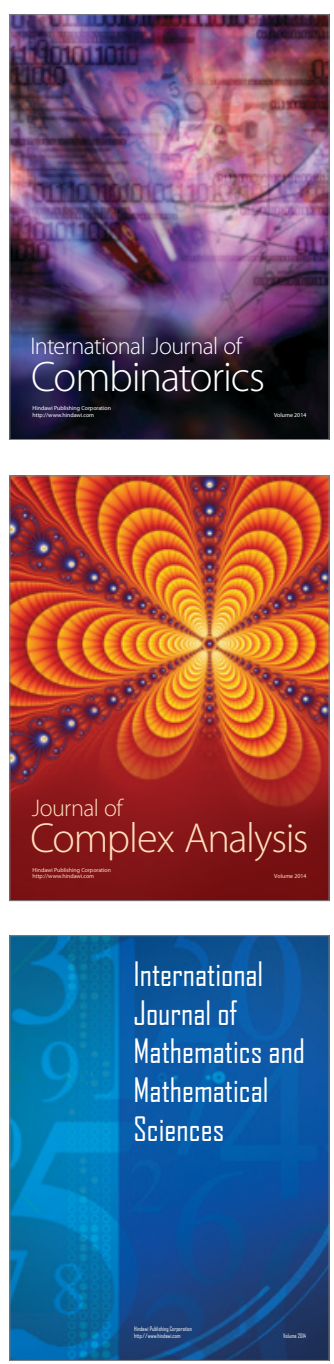
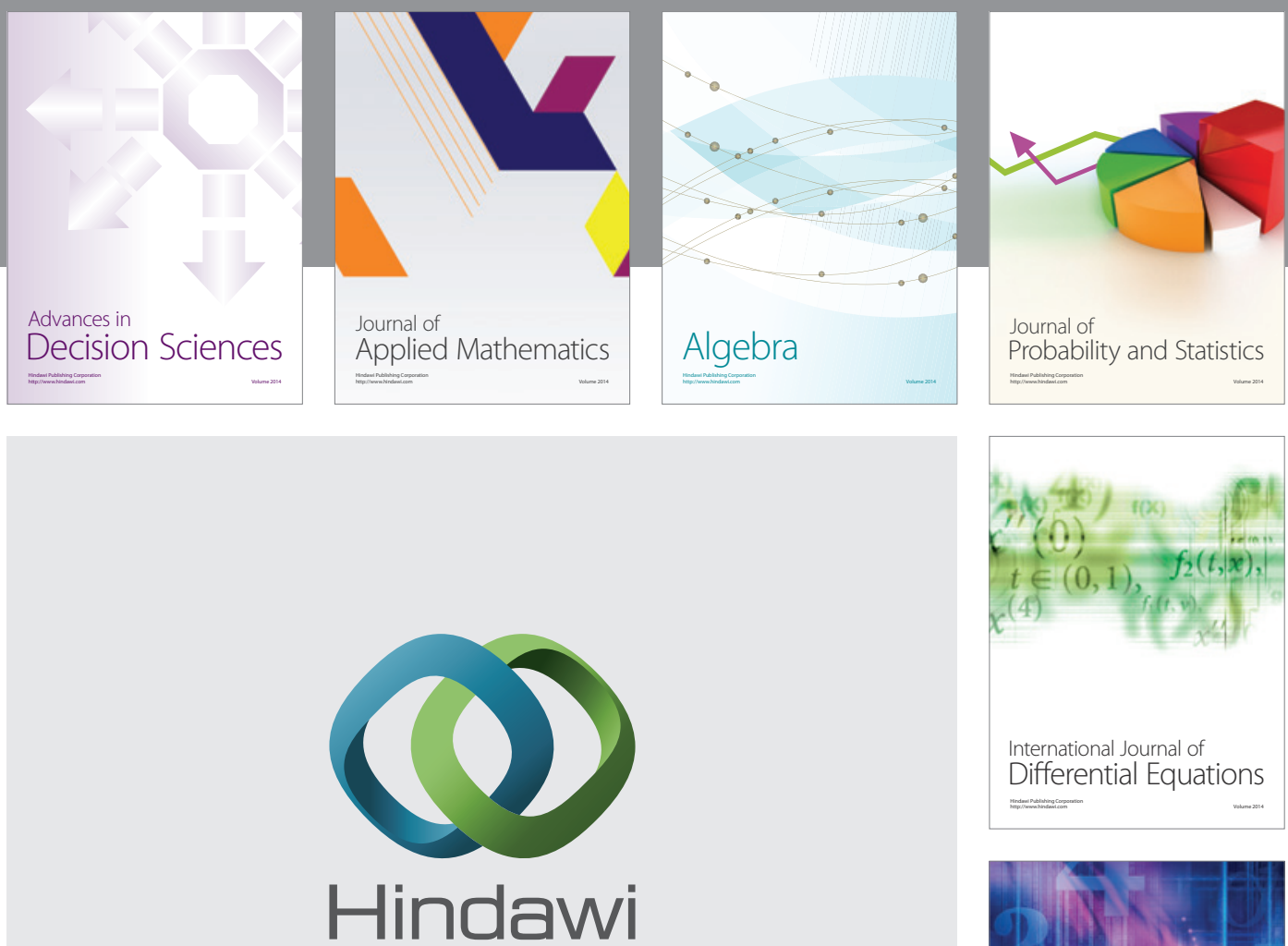

Submit your manuscripts at http://www.hindawi.com
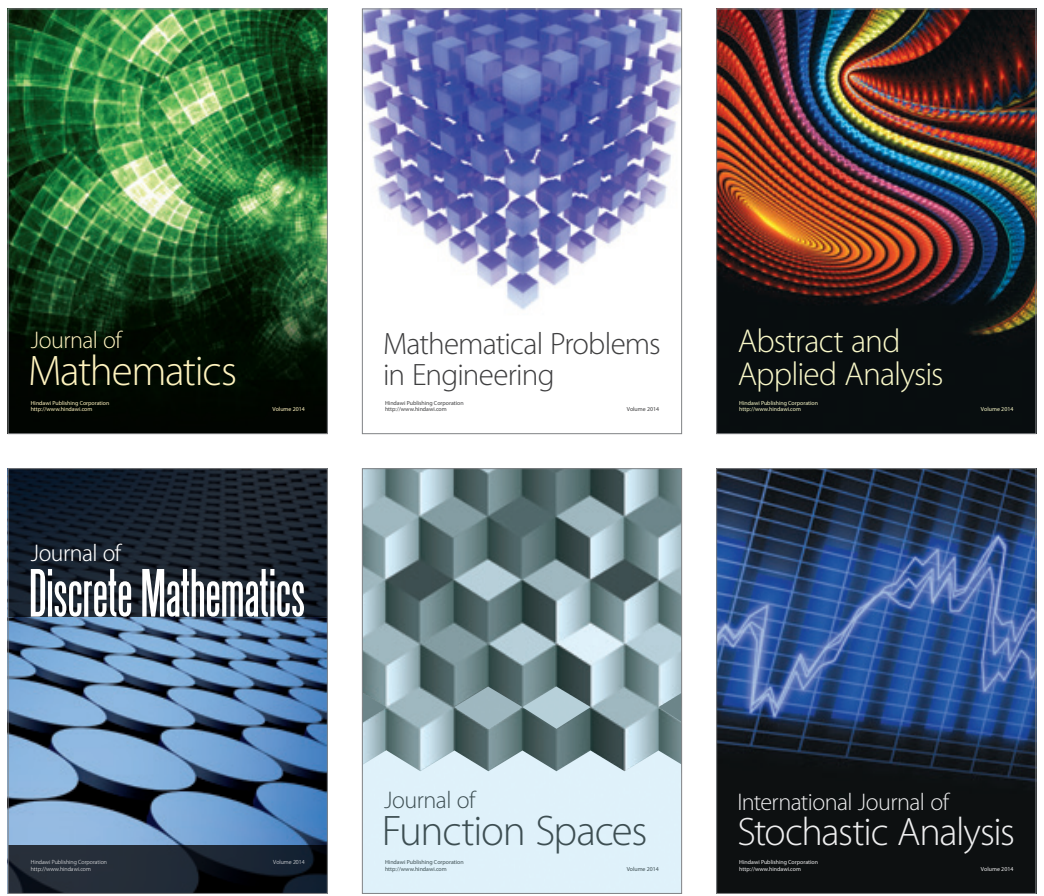

Journal of

Function Spaces

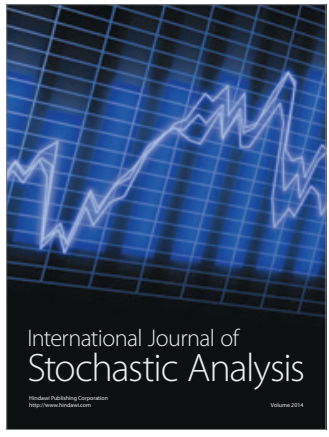

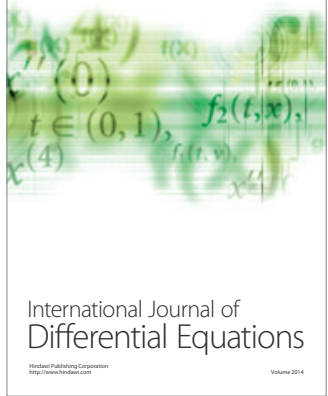
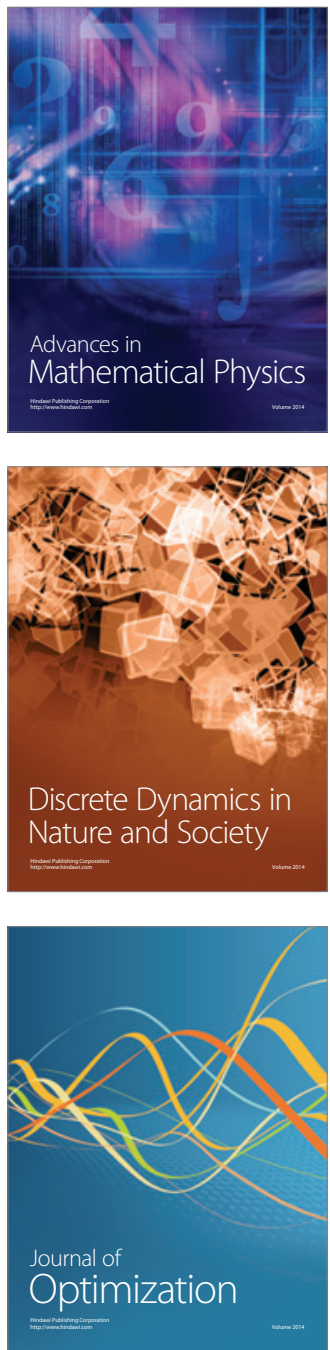